\title{
Análise da eficiência de Companhias Aéreas Brasileiras'
}

\author{
Breno Sampaio" \\ André de Souza Melo"*
}

\begin{abstract}
Resumo: A eficiência das companhias aéreas brasileiras é estimada utilizando metodologia DEA. Os insumos utilizados foram número de empregados, combustível consumido e custo operacional da companhia e produtos foram passageiros transportados, receitas e utilização dos assentos. Obtidas as eficiências, utilizaram-se modelos de regressão para analisar variáveis que influenciam as mesmas. Os resultados mostraram aumento da eficiência média ao longo do tempo. Dentre as seis maiores companhias, somente três operavam, em 2004, na fronteira eficiente: GOL, TAM e VARIG. A eficiência das companhias é significativamente afetada por custo por passageiro, percentual de mercado e pessoal por passageiro.
\end{abstract}

Palavras-Chave: Companhias Aéreas, Transporte Aéreo, Análise de Eficiência.

Abstract: Efficiency of Brazilian airlines are estimated using Data Envelopment Analysis (DEA) method. Number of employees, oil consumption and operational costs are selected as inputs and number of passengers, total revenue and seats occupation as outputs. Regression models were estimated to analyze which variables explain efficiency variance. Results show that average efficiency increased through time. Among the six larger companies in 2004, only GOL, TAM and VARIG operated on the efficiency frontier. Regression analyses pointed that cost per passenger, market participation and employees per passenger significantly affect airlines efficiency.

Keywords: Brazilian Airlines, Air Transport, Efficiency Analysis.

JEL Classification: C61; L93.

\section{Introdução}

O setor aéreo brasileiro representa aproximadamente 3\% do PIB nacional, com impacto direto de US\$ 6,7 bilhões e indireto de US\$ 18 bilhões, gerando 35.000 empregos diretos (IPEA, 2002). Desde o final dos anos 70 até os dias atuais, a participação do transporte aéreo

1 Os autores agradecem sugestões de Yony Sampaio, Everardo Sampaio e Eduardo Medicis.

* Department of Economics, University of Illinois at Urbana Champaign. E-mail: brenosampaio@ hotmail.com

** UFPE. Email: andredesouzam@gmail.com 
na matriz de transportes brasileira passou de $0,7 \%$ para $2,7 \%$. A taxa de crescimento foi de 6,6\% ao ano entre 1997 e 2000 . O auge desse crescimento ocorreu no ano de 1998, quando houve um crescimento de 22\% no setor doméstico (PASIN; LACERDA, 2003 apud PINTO, 2003)

A explicação para esse crescimento elevado deve-se em grande parte a maior abertura do mercado quanto às barreiras existentes para o surgimento de novas companhias e a desregulamentação iniciada na década de 90 (COELHO, 2002 apud SOARES de MELLO et al., 2003). Com o surgimento dessas novas companhias aéreas e a modernização das já existentes, foi possível aumentar o número de assentos disponíveis na malha aérea e elevar o nível de competição entre as companhias. Essa competição é bastante benéfica do ponto de vista do usuário, pois possibilitou melhoria significativa do serviço e induziu uma redução elevada das tarifas. A competição também teve impacto no modo de gestão das companhias que agora se baseiam na demanda para definir suas metas.

Porém, algumas empresas começaram a enfrentar grandes dificuldades no final da década de 90 e início do século XXI revelando-se bastante ineficientes. Estas dificuldades se deram devido ao aumento dos custos e da redução da demanda. Segundo Pinto (2003), a desvalorização do Real, iniciada em 1999, afetou duramente o setor, uma vez que seus principais insumos são cotados em dólar. Deve-se somar a isso as oscilações nos preços do petróleo, que afetam diretamente o custo dos combustíveis e, mais recentemente, a retração geral na economia, com a conseqüente queda da renda da população e aumento no desemprego, que fez com que a demanda de transporte aéreo se retraísse bastante. Em período mais recente a valorização do real e o aumento da demanda reverteram o quadro negativo mas em presença de uma feroz competição entre as companhias.

Nesse contexto, o objetivo desse trabalho é analisar alguns aspectos que afetam o desempenho das companhias aéreas brasileiras. Para tanto, foram calculados os coeficientes de eficiência pelo método da análise envoltória de dados - DEA. Depois de obtidos os coeficientes, foi utilizado modelo econométrico para analise de variáveis que influenciam a eficiência.

A respeito dos impactos da desregulamentação do mercado de transporte, Caves, Christensen e Tretheway (1984) estudaram o desempenho de pequenas companhias em relação a grandes companhias americanas após a desregulamentação do mercado doméstico americano. Para tanto, estudaram as diferenças de custos das grandes e pequenas companhias com o objetivo de analisar se as pequenas podem competir com as grandes, apesar das grandes diferenças de custo. 
Construíram um modelo geral de custo de serviços para distinguir os efeitos de economias de escala e da densidade. Ao contrário do que foi esperado, as pequenas companhias puderam competir em igualdade de condições com as grandes companhias no período pósdesregulamentação. Martín, Nombela e Romero (1999) analisaram a estrutura de custos das companhias aéreas com o objetivo de medir o impacto do processo da desregulamentação na eficiência das companhias. Concluíram que a diferença de custos, que não foi grande, depende fundamentalmente dos preços dos inputs, em especial, capital e trabalho. O caso brasileiro é mais complexo pois a desregulamentação foi parcial - tem sido estimulada a competição mas as rotas ainda são concessão do órgão regulador.

Um número limitado de trabalhos foi realizado calculando eficiência com uso do método DEA, em particular para companhias brasileiras só foi encontrado um único trabalho. Soares de Mello et al., (2003) avaliaram a eficiência de companhias aéreas brasileiras utilizando o método da análise envoltória de dados com retornos variáveis de escala. Consideraram três modelos distintos de eficiência: modelo operacional, modelo de vendas e um modelo global. No modelo global, utilizaram como inputs: combustível usado, soma das capacidades de passageiros do total das aeronaves da frota e quantidade total de pessoal; e como output passageiro.Km pagos. Os dados que utilizaram referem-se aos anos de 1998 a 2000, disponibilizados pelo Departamento de Aviação Civil (DAC). Chegaram à conclusão que a separação em três modelos de análise de eficiência permitiu uma desagregação de variáveis, levando à descoberta de eficiências não evidentes e à explicação de algumas ineficiências.

Após esta breve introdução, na próxima seção são descritos a metodologia DEA, as companhias aéreas analisadas, os dados e variáveis, assim como os modelos econométricos utilizados e seus métodos de estimação. Na terceira seção, têm-se a análise e apresentação dos resultados da metodologia DEA e dos modelos econométricos utilizados. Por fim, na quarta seção são apresentadas as conclusões obtidas.

\section{Metodologia}

Os coeficientes de eficiência das companhias aéreas brasileiras foram calculados pelo método da análise envoltória de dados - DEA, que é apresentado no item a seguir. Depois são descritos as companhias aéreas analisadas, os dados e as variáveis utilizadas. Em seguida, faz-se discussão sobre o modelo econométrico utilizado e seu método 
de estimação para apontar influencias de alguns fatores na eficiência das companhias.

\subsection{Análise Envoltória de Dados}

A eficiência das companhias aéreas brasileiras foi determinada pelo método de análise de envoltória de dados - DEA (Data Envelopment Analysis). Neste método, as companhias aéreas são considerados unidades tomadoras de decisão (Decision Making Units - DMUs) que são avaliadas por suas eficiências relativas às unidades identificadas como eficientes e que compõem a fronteira tecnológica. De acordo com a forma da fronteira, têm-se duas abordagens distintas - a paramétrica e a não-paramétrica. No primeiro caso, postula-se que a fronteira do conjunto produtivo pode ser representada por uma função de produção caracterizada por parâmetros constantes. Este método foi utilizado, pioneiramente, por Aigner e Chu (1968). Com isso, uma forma funcional é definida a priori para a tecnologia e a estimação é feita, normalmente, através de métodos econométricos. A especificação da função de produção é a maior limitação da abordagem paramétrica, uma vez que as medidas de eficiência podem variar muito de acordo com a função escolhida. A forma não-paramétrica não se baseia em uma função especificada a priori. A forma da fronteira do conjunto produtivo é determinada considerando que o conjunto de produção deve satisfazer determinadas propriedades. $\mathrm{O}$ método DEA está inserido na abordagem não-paramétrica, e emprega o método de programação matemática para estimar modelos de fronteiras de produção e obter os escores de eficiência. Este método é baseado no trabalho de Farrell (1957), posteriormente popularizado por Charnes et al., (1978).

No DEA, as DMUs realizam tarefas similares e se diferenciam pelas quantidades dos insumos que consomem e dos produtos que resultam. Supõe-se que o conjunto de possibilidade de produção, como se mencionou anteriormente, deve satisfazer determinadas propriedades, ou seja, não há suposições sobre a fronteira propriamente dita. O conjunto de produção é limitado pela fronteira de produção composta por aquelas DMUs que são eficientes. A determinação das DMUs eficientes é feita através da resolução, para cada uma delas, de um sistema de equações lineares definido para mensurar o nível de eficiência de cada DMU.

O modelo proposto por Charnes et al. (1978), com retornos constantes de escala, pode ser resumido supondo-se $\mathrm{N}$ firmas ou 
DMUs utilizando I insumos para produzir $\mathrm{P}$ produtos. $\mathrm{O}$ índice $\mathrm{i}$ indica a i-ésima DMU, para a qual os vetores $x_{i}$ e $y_{i}$ representam a quantidade de insumos e produtos. O objetivo é construir uma fronteira não paramétrica que envelope os dados, de forma que todas as unidades se encontrem sobre ou abaixo desta fronteira. Para cada DMU é maximizada a razão entre a soma ponderada dos produtos e a soma ponderada dos insumos, onde u é um vetor Px1 dos pesos associados ao produto e $\mathrm{v}$ um vetor IxI dos pesos associados aos insumos. Os valores de u e v são tratados como incógnitas e calculados de forma a maximizar a eficiência de cada DMU. Para cada DMU é desenvolvido o seguinte problema:

$$
\begin{aligned}
& \operatorname{Max}_{u, v}\left(u^{t} y_{i} / v^{t} x_{i}\right), \\
& \text { sujeito a }\left(u^{t} y_{j} / v^{t} x_{j}\right) \leq 1, j=1, \ldots, N, \\
& u \geq 0 \text { e } v \geq 0
\end{aligned}
$$

O modelo descrito acima apresenta um número infinito de soluções. Pois, se $\left(u^{*}, v^{*}\right)$ é uma solução do problema, então ( $\alpha u^{*}$, $\left.\alpha v^{*}\right)$ também é uma solução possível. Esse problema foi resolvido por Charnes et al. (1978) impondo a condição $v^{t} x_{i}=1$. Dessa forma, o novo problema de programação linear é:

$$
\begin{aligned}
& \operatorname{Max}_{u, v} u^{t} y_{i}, \\
& \text { sujeito a } v^{t} x_{j}=1, \\
& u^{t} y_{j}-v^{t} x_{j} \leq 0, j=1, \ldots, N, \\
& u \geq 0 \text { e } v \geq 0
\end{aligned}
$$

Essa nova forma é conhecida como forma multiplicativa e apresenta um grande número de restrições, não sendo adequada para efeitos computacionais. Utilizando a propriedade da dualidade da programação linear, o problema pode ser formulado de uma forma equivalente, porém com menos restrições $(\mathrm{I}+\mathrm{P}<\mathrm{N}+1)$ :

$$
\begin{array}{ll}
\text { Min }_{\theta, \lambda} \theta, & \text { onde } \theta \text { : escore de eficiência; } \\
\text { sujeito a } \mathrm{Y} \lambda-\mathrm{yi} \geq 0, & \lambda \text { : vetor Nx1 de constantes; } \\
\theta \mathrm{x}_{\mathrm{i}}-\mathrm{X} \lambda \geq 0, & \mathrm{X} \text { : matriz dos insumos (IxN); } \\
\lambda \geq 0 . & \mathrm{Y} \text { : matriz dos produtos }(\mathrm{PxN}) .
\end{array}
$$

O problema de programação linear é resolvido $\mathrm{N}$ vezes, uma para cada DMU. $\mathrm{O}$ valor de $\theta$ é o escore de eficiência e deve satisfazer a condição $\theta \leq 1$.

O uso de retornos constantes de escala, quando nem todas as DMUs estão operando na escala ótima, resulta em medidas de eficiência técnica influenciadas pelas medidas de eficiência de escala. Nestes 
casos, a abordagem por retornos variáveis de escala permite a medição da eficiência técnica sem a interferência da eficiência de escala.

A extensão desse modelo, passando a considerar rendimentos variáveis de escala (VRS), foi feita por Banker et al. (1984), adicionando a restrição de convexidade $\left(z^{t} \lambda=1\right)$, obtendo o seguinte problema:

$$
\begin{aligned}
& \text { Min }{ }_{\theta, \lambda} \theta, \\
& \text { sujeito a } \mathrm{Y} \lambda-\mathrm{yi} \geq 0, \quad \text { onde } z \text { : vetor unitário } \mathrm{N} \times 1 . \\
& \theta \mathrm{x}_{\mathrm{i}}-\mathrm{X} \lambda \geq 0, \\
& \lambda \geq 0 .
\end{aligned}
$$

Convém registrar que uma das vantagens da metodologia DEA, quando usada para medir a eficiência técnica, é que ela pode produzir automaticamente "unidades alvos" sempre que encontrar unidades ineficientes. Tais "unidades alvos" podem ser "virtuais" e não necessariamente uma DMU existente, ou seja, a "unidade alvo" pode ser uma combinação linear das unidades eficientes em relação à DMU ineficiente. Assim a metodologia DEA estabelece que uma determinada DMU é ineficiente e identifica as DMUs para as quais esta unidade é ineficiente. Há, então, a determinação de um conjunto de pesos $\lambda$ indicando uma combinação de unidades eficientes e representando a proporção em que o produto da unidade ineficiente poderia ser produzido usando menos insumos, em relação às "unidades alvos" (RÉGIS, 2001).

\subsection{Companhias Aéreas Analisadas, Dados e Variáveis}

Foram analisadas 23 companhias brasileiras de transporte aéreo. A escolha dessas companhias se deu primeiramente pela entidade aeronáutica (DAC - Departamento de Aviação Civil) que não considera regulares algumas companhias como, por exemplo, a Umas e, portanto, não há disponibilidade de dados. Segundo, também foram desconsideradas companhias como Skymaster, ABSA, Brasmex, TAF, Variglog e Itapemirim por serem companhias que operam exclusivamente no transporte de carga. Ou seja, este estudo concentra-se em companhias que operam no transporte de passageiros, pois, segundo Burmann (2000) o setor de carga tem ainda pequena importância no Brasil.

Os dados foram obtidos nos anuários de dados estatísticos do Departamento de Aviação Civil para os anos de 1998 a 2004. Foi considerado que cada companhia é uma DMU diferente em cada ano. 
Isto se justifica pelo fato de que se a mesma companhia, em anos distintos, for analisada na mesma fronteira de produção, pode-se obter a evolução temporal de sua eficiência. Esta hipótese, no entanto, pode ser utilizada somente se a tecnologia usada não teve variações substanciais, o que, no caso do transporte aéreo brasileiro, é válido. O número final de DMUs analisadas, considerando DMUs distintas para a mesma companhia em anos distintos, foi de 117.

Durante os anos de análise, algumas companhias foram criadas e outras deixaram de existir. As companhias que surgiram no período foram GOL, OceanAir, Puma Air e TRIP. Destas, a companhia que tem apresentado maior crescimento é a GOL que, quando começou a operar em janeiro de 2001 detinha 4,5\% do mercado e, em 2004, transportou pouco mais de $20 \%$ do total de passageiros transportados no Brasil. Das companhias que deixaram de existir, uma das principais é a Transbrasil que deixou de operar em 2001 e vinha desde 1998 sofrendo drástica queda em seu percentual de mercado. Em 1998, detinha quase $11 \%$ do mercado, passando para quase 10\% em 1999, depois para 7,7\% em 2000 e, por fim, 4,7\% em 2001.

A escolha de indicadores chaves que permitam a avaliação da performance das companhias de transporte aéreo brasileiras e a comparação entre elas através de modelos matemáticos, sendo o DEA um dos mais utilizados, tem sido uma busca de diversos autores, pois, o grande número de variáveis que podem ser utilizadas impossibilita uma comparação mais direta entre as companhias, não permitindo a generalização dos resultados (BENJAMIN; OBENG, 1990).

A escolha dos insumos e produtos para calcular a eficiência das companhias de transporte aéreo foi dada pela disponibilidade de dados e pela revisão dos trabalhos já realizados. O modelo adotado é apresentado na figura 1. O primeiro insumo é trabalho, bastante indicado pela literatura, que pode ser representado pelo número total de empregados (pilotos e co-pilotos, demais tripulantes técnicos, auxiliares de vôo, pessoal de manutenção, de revisão, de trafego e de vendas e outros) ou, alternativamente, pelos custos de mão de obra. Em nosso caso foi utilizado número total de empregados. O segundo insumo é consumo de combustível, outra variável bastante indicada, sendo medida diretamente pela quantidade anual total utilizada pela companhia em litros. O terceiro insumo é custo operacional da companhia, dado em reais. Os produtos (outputs) adotados são: passageiros transportados, receitas e percentual de utilização dos assentos. O percentual de utilização dos assentos é dado pela razão entre o nú- 
Figura 1. Variáveis Utilizadas no Método DEA

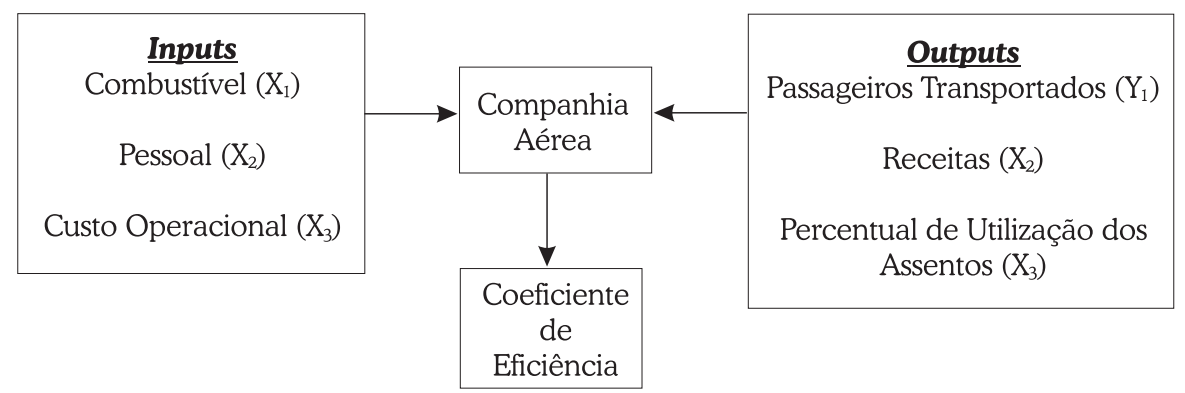

mero total de assentos disponibilizados pela companhia ao longo do ano e o número de assentos que foi realmente ocupado por passageiros.

Neste artigo adotou-se o modelo orientado para produto, de forma a otimizar o uso de recursos, como possibilidades de adotar outras formas de venda para reduzir o quadro de funcionários, adotar aeronaves mais econômicas do ponto de vista de consumo de combustível, etc, com vistas a maximizar a produção, por exemplo, aumentando o número de passageiros transportados. E ainda que, em virtude da grande variação nos tamanhos e características de cada companhia analisada, optou-se pelo modelo DEA com Retornos Variáveis de Escala (DEA-VRS).

\subsection{Modelo Econométrico}

Depois de obtidos os coeficientes de eficiência das companhias aéreas (EFIC) pelo método DEA, estes foram analisados através de modelos econométricos relacionando eficiência a cinco variáveis: quantidade de combustível gasto por $\mathrm{km}$ voado (COMB), custo por passageiro (CUSTO), uma variável dummy para identificar se a companhia opera com vôos internacionais ou não (VI), o percentual de mercado que a companhia detém (MERC) e a quantidade de pessoal empregado por passageiro (PP).

Os modelos a serem estimados são do tipo:

$$
\begin{aligned}
& \text { Modelo 1: EFIC }=\beta_{0}+\beta_{1} C O M B+\beta_{2} V I+\beta_{3} C U S T O+\varepsilon_{t} \\
& \text { Modelo 2: } E F I C=\beta_{0}+\beta_{1} P P+\beta_{2} M E R C+\varepsilon_{t}
\end{aligned}
$$


Para melhor ajustamento do modelo foram utilizados modelos separados, pois foi encontrado problema de multicolinearidade entre os regressores que impactam na eficiência. A relação linear encontrada foi entre MERC e COMB, PP e CUSTO. O método utilizado para encontrar multicolinearidade foi o de regressões auxiliares entre os regressores. Aquela regressão que obtém um $\mathrm{r}^{2}$ maior do que o $\mathrm{R}^{2}$ da regressão com todas as variáveis explicativas, apresenta multicolinearidade.

O consumo de combustível por km voado é uma variável bastante importante no que diz respeito à lucratividade e eficiência das companhias. É de se esperar que quanto menos combustível por km voado a companhia consumir, maior lucro e eficiência terá. Segundo o Jornal da Globo (2006), os gastos com combustível representam, nas grandes companhias, 33\% do valor cobrado nas passagens. Este consumo é afetado por diversos fatores. O peso que a aeronave está carregando é um deles: quanto maior o peso, maior consumo. Outro fator é o tipo da aeronave utilizada. Os tipos têm grandes variações quanto ao número de turbinas utilizadas e aerodinâmica, que afetam a altitude do vôo. O número de turbinas está diretamente ligado ao consumo de combustível, quanto mais turbinas, maior seu valor. A aerodinâmica da aeronave afeta o atrito que por sua vez aumenta o consumo.

A distância e a altitude do vôo também são determinantes no consumo de combustível. A tabela 1 mostra o consumo do Boeing 737-600 em função da distância a ser voada e da altitude do vôo. Pode-se observar que, para uma mesma distância aérea, a razão entre o consumo de combustível e a distância do vôo diminui à medida que se aumenta a altitude do vôo, ou seja, quanto mais alto for o vôo menor seu consumo por km. Outra constatação importante diz respeito à distância a ser percorrida: para uma mesma altitude, quanto maior a distância, menor o consumo por $\mathrm{km}$. Isto se justifica pelo fato de que o maior consumo de combustível da aeronave é na decolagem, ou seja, quanto maior a distância a ser percorrida, menor o consumo por $\mathrm{km}$.

Outro fator que afeta o consumo de combustível é a formação de gelo, que aumenta consideravelmente o peso e o atrito da aeronave. Essa formação se dá em duas ocasiões: presença no ar de gotículas de água no estado líquido a temperaturas abaixo de $0^{\circ} \mathrm{C}$ (gotículas superesfriadas) e temperatura da superfície externa da aeronave a $0^{\circ} \mathrm{C}$ ou menor. 
Tabela 1. Consumo de Combustível em Litros do Boeing 737-600

\begin{tabular}{|c|c|c|c|c|c|c|c|c|c|c|}
\hline \multirow{3}{*}{\begin{tabular}{|c|} 
Distância Aérea \\
$(\mathrm{NM})$ \\
\end{tabular}} & \multicolumn{10}{|c|}{ Altitude $\left({ }^{*} 1000 \mathrm{FT}\right)$} \\
\hline & \multicolumn{2}{|c|}{29} & \multicolumn{2}{|c|}{31} & \multicolumn{2}{|c|}{33} & \multicolumn{2}{|c|}{35} & \multicolumn{2}{|c|}{37} \\
\hline & $\mathrm{L}$ & $\mathrm{L} / \mathrm{NM}$ & $\mathrm{L}$ & $\mathrm{L} / \mathrm{NM}$ & $\mathrm{L}$ & L/NM & $\mathrm{L}$ & $\mathrm{L} / \mathrm{NM}$ & $\mathrm{L}$ & L/NM \\
\hline 200 & 1395 & 6,98 & 1395 & 6,98 & 1395 & 6,98 & 1395 & 6,98 & 1395 & 6,98 \\
\hline 400 & 2385 & 5,96 & 2385 & 5,96 & 2385 & 5,96 & 2295 & 5,74 & 2295 & 5,74 \\
\hline 600 & 3375 & 5,63 & 3375 & 5,63 & 3285 & 5,48 & 3285 & 5,48 & 3195 & 5,33 \\
\hline 800 & 4455 & 5,57 & 4365 & 5,46 & 4275 & 5,34 & 4185 & 5,23 & 4050 & 5,06 \\
\hline 1000 & 5445 & 5,45 & 5355 & 5,36 & 5175 & 5,18 & 5040 & 5,04 & 4950 & 4,95 \\
\hline 1200 & 6435 & 5,36 & 6345 & 5,29 & 6165 & 5,14 & 6030 & 5,03 & 5940 & 4,95 \\
\hline 1400 & 7560 & 5,4 & 7335 & 5,24 & 7155 & 5,11 & 7065 & 5,05 & 6840 & 4,89 \\
\hline 1600 & 8640 & 5,4 & 8325 & 5,2 & 8145 & 5,09 & 7920 & 4,95 & 7875 & 4,92 \\
\hline 1800 & 9630 & 5,35 & 9405 & 5,23 & 9135 & 5,08 & 8910 & 4,95 & 8730 & 4,85 \\
\hline 2000 & 10710 & 5,36 & 10395 & 5,2 & 10125 & 5,06 & 9810 & 4,91 & 9630 & 4,82 \\
\hline 2200 & 11790 & 5,36 & 11520 & 5,24 & 11205 & 5,09 & 10935 & 4,97 & 10620 & 4,83 \\
\hline 2400 & 12915 & 5,38 & 12600 & 5,25 & 12195 & 5,08 & 11925 & 4,97 & 11610 & 4,84 \\
\hline 2600 & 13995 & 5,38 & 13590 & 5,23 & 13275 & 5,11 & 12915 & 4,97 & 12600 & 4,85 \\
\hline 2800 & 15165 & 5,42 & 14670 & 5,24 & 14265 & 5,09 & 13905 & 4,97 & 13590 & 4,85 \\
\hline Média & 8137,4 & & 7935,1 & & 7729,5 & & 7546,4 & & 7382,6 & \\
\hline
\end{tabular}

Fonte: Cruise Flight - Aircraft Operating Manual 737-600, 2003.

O custo por passageiro está ligado a diversos fatores. Quanto menor custo a companhia conseguir operar por passageiro melhor deve ser seu desempenho. Os custos incluem folha de pagamento e encargos, tarifas aeroportuárias e custo operacional. O custo com o pessoal é dado pelo número de pilotos e co-pilotos, demais tripulantes técnicos, auxiliares de vôo, pessoal de manutenção, de revisão, de trafego e de vendas e outros. Várias companhias vêm reduzindo o número de pessoal responsável pela parte de vendas e pela parte de manutenção e revisão. A GOL, por exemplo, tem parcela bastante significativa de vendas de passagens via Internet. Com relação ao pessoal de manutenção, companhias têm adotado um mesmo modelo de aeronave, que reduz gastos com treinamento de pessoal, assim como reduz o número de funcionários. As tarifas aeroportuárias dependem do tempo que a aeronave gasta no aeroporto, ou seja, quanto mais tempo a aeronave passar em vôo mais lucro terá, visto que as tarifas serão menores e a empresa estará lucrando com a viagem. Por outro lado, um avião representa um custo elevado, comprado ou em forma de leasing, e quanto mais voar menor o custo unitário. O custo operacional inclui diversos itens. Pode-se citar, por exemplo, o custo com refeições a bordo. Cada refeição custa em média 6 reais que, quando multiplicados pelo número de passageiros transportados ao longo do ano, tem impacto bastante elevado nos lucros.

A variável dummy identifica se a companhia opera somente em vôos domésticos ou se opera em vôos domésticos e também em vôos internacionais. Foi atribuído valor de 1 para as companhias que operam com vôos nacionais e internacionais e valor 0 para as companhias que operam somente dentro do Brasil. Com relação a sua influência, há dois argumentos. De um lado, há companhias regionais 
que por dominarem o transporte na região e usarem aeronaves mais uniformes e mais econômicas tem elevado sua eficiência. Por outro lado, companhias que operam internacionalmente estão mais bem protegidas contra variações sazonais de mercado, além de poderem combinar melhor a operação de distintas aeronaves. O gasto total é muito mais elevado, mas pode obter igualmente retornos elevados. Adicionalmente, como o transporte internacional opera com rotas concedidas, às vezes é possível impor ágios às tarifas cobradas. Mas as companhias ficam muito sujeitas a variações no câmbio, em paises em que ocorrem defasagens entre o câmbio real e a taxa de câmbio nominal.

O percentual de mercado da companhia pode ter impactos positivos e negativos. Em princípio, no mercado da aviação é possível ser eficiente sendo grande ou pequeno. Mais importante que o tamanho em si é a variação nesta participação. Companhias em crescimento, em geral, o fazem por serem eficientes. Companhias em contração estão buscando ajustamento para elevar a eficiência e restaurar a lucratividade.

O número de funcionários por passageiro sofre influencias, de um lado, do número de passageiros transportados; ou seja, quanto maior o número de passageiros, dado o pessoal fixo empregado, maior a eficiência. Por outro lado, dado um número de passageiros, a companhia será mais eficiente quanto menor for o número de funcionários empregados. A grande novidade, em período recente, tem sido a venda de passagens on-line, que tanto eleva a tarifa retida (não há participação de agências de viagens) como reduz o pessoal em terra.

\subsection{Método de Estimação}

A utilização de dados de corte transversal sugere que haja a presença de heteroscedasticidade, problema muito comum neste tipo de dados. Heteroscedasticidade causa problemas de inferência na regressão, pois os coeficientes estimados, apesar de serem não viesados e consistentes, não possuem variância mínima. Isso resulta que o coeficiente $\beta$ não é o melhor estimador linear não viesado (MELNV). Para identificar este problema foi utilizado o Teste de Goldfeld - Quandt. Este consiste em testar se a variância é proporcional ao quadrado da variável que pode estar causando heteroscedasticidade. Se isto for verdade, significaria que a variância seria tanto maior quanto maiores os valores do regressor analisado. Para testar isto explicitamente, o método sugere: i) ordenar as observações de acordo com os valores da variável que se suspeita estar causando heteroscedasticidade, começando pelo seu valor mais baixo; ii) omitir 
as observações centrais $c$, em que $c$ é especificado a princípio e dividir as $(n-c)$ observações restantes em dois grupos, cada um com $(n-$ c)/2 observações.; iii) ajustar as distintas regressões dos dois grupos por Mínimos Quadrados Ordinários (MQO), obtendo as somas dos quadrados dos resíduos de (SQR) para cada uma delas. Cada uma das SQR tem [(n-c)/2] - $\mathrm{k}$ graus de liberdade, em que $\mathrm{k}$ é o número de parâmetros a serem estimados; iv) calcular a razão SQR (grupo 2) dividido pelo número de graus de liberdade sobre $S Q R$ (grupo 1) dividido pelo número de graus de liberdade. Esta razão segue a distribuição $\mathrm{F}$ com gl de $(\mathrm{n}-\mathrm{c}-2 \mathrm{k}) / 2$ no numerador e denominador. Se o F calculado for maior que o F crítico, pode-se rejeitar a hipótese de homoscedasticidade (GUJARATI, 2000).

Uma vez identificado problema da estimação, o método utilizado para corrigir a heteroscedasticidade é o modelo de mínimos quadrados ponderados (MQP). De acordo com este método, a equação a ser estimada deve ser ponderada por pesos inversamente proporcionais à variância do erro. Considerando um modelo no qual foi encontrada evidência estatística da ocorrência de heteroscedasticidade, o estimador de MQP é:

$$
\hat{\beta}=\left(X^{\prime} \Omega^{-1} X\right)^{-1} X^{\prime} \Omega^{-1} y
$$

onde $\Omega^{-1}$ é uma matriz diagonal na qual o i-ésimo elemento diagonal é $1 / w$. Assim, o estimador de MQP é obtido pela regressão de:

$$
\mathrm{Py}=\left[\begin{array}{c}
y_{1} / \sqrt{\omega_{1}} \\
y_{2} / \sqrt{\omega_{2}} \\
\vdots \\
y_{n} / \sqrt{\omega_{n}}
\end{array}\right] \quad \text { e } \quad \mathrm{PX}=\left[\begin{array}{c}
\mathrm{x}_{1} / \sqrt{\omega_{1}} \\
\mathrm{x}_{2} / \sqrt{\omega_{2}} \\
\vdots \\
\mathrm{x}_{\mathrm{n}} / \sqrt{\omega_{n}}
\end{array}\right]
$$

onde $\mathrm{P}=1 / \sqrt{\omega_{1}}$ é um ponderador da regressão. Aplicando-se mínimos quadrados ordinários ao modelo transformado, obtém-se os estimadores de mínimos quadrados ponderados. Na prática, o peso w pode ser uma das variáveis explicativas ou o seu quadrado (GREENE, 2003).

\section{Análise e Resultados}

Os escores de eficiência das companhias aéreas obtidos estão apresentados na tabela 2 . 
Tabela 2. Escore de Eficiência das Companhias

\begin{tabular}{|c|c|c|c|c|c|c|c|}
\hline & 2004 & 2003 & 2002 & 2001 & 2000 & 1999 & 1998 \\
\hline ABAETÉ & 1 & 1 & 1 & 0,96 & 0,89 & 1 & 1 \\
\hline GOL & 1 & 1 & 0,54 & 0,59 & - & - & - \\
\hline META MESQUITA & 1 & 0,95 & 1 & 0,79 & 0,81 & 1 & - \\
\hline NORDESTE & 0,62 & 0,65 & 0,7 & 0,73 & 0,82 & 0,75 & 0,73 \\
\hline OCEANAIR & 0,53 & 0,5 & - & - & - & - & - \\
\hline PENTA & 1 & 0,9 & 0,82 & 0,62 & 0,76 & 0,71 & 1 \\
\hline PUMA AIR & 0,86 & 0,66 & 0,87 & - & - & - & - \\
\hline PANTANAL & 0,68 & 0,67 & 1 & 0,69 & 0,66 & 0,49 & 0,54 \\
\hline $\mathrm{RICO}$ & 0,79 & 0,77 & 0,74 & 0,77 & 0,84 & 0,84 & 0,91 \\
\hline RIOSUL & 0,62 & 0,56 & 0,68 & 0,69 & 0,87 & 0,97 & 0,8 \\
\hline TAM & 1 & 1 & 1 & 1 & 1 & 1 & 0,89 \\
\hline TRIP & 1 & 1 & 0,94 & 0,79 & - & - & - \\
\hline TOTAL & 0,67 & 0,94 & 0,6 & 1 & 0,65 & 0,67 & 0,55 \\
\hline TAVAJ & 0,72 & 0,54 & 0,53 & 0,54 & 0,5 & 0,54 & 1 \\
\hline VARIG & 1 & 1 & 0,9 & 0,83 & 0,89 & 0,81 & 0,82 \\
\hline VASP & 0,48 & 0,72 & 0,66 & 0,73 & 0,65 & 0,6 & 0,79 \\
\hline INTERBRASIL & - & - & - & 0,77 & 1 & 0,99 & 0,56 \\
\hline PASSAREDO & - & - & - & 0,59 & 0,53 & 0,84 & 0,6 \\
\hline TRANSBRASIL & - & - & - & 0,56 & 0,59 & 0,54 & 0,55 \\
\hline PRESIDENTE & - & - & - & - & 1 & 1 & 1 \\
\hline TAF & - & - & - & - & 1 & 0,64 & 0,72 \\
\hline TABA & - & - & - & - & - & 0,38 & 0,38 \\
\hline MERIDIONAIS & - & - & - & - & - & - & 1 \\
\hline
\end{tabular}

Fonte: Software EMS.

A evolução da eficiência média ou global ao longo dos anos das companhias aéreas brasileiras é apresentada no gráfico 1. Observase que esta eficiência global se mostra com leve tendência de crescimento, somente interrompida no ano de 2001. Segundo Jornal da Globo (2006), "a aviação comercial no Brasil segue na contramão da tendência mundial. Mais passageiros, novas empresas chegando ao mercado e aumento de lucros. O setor está não apenas crescendo, mas se reorganizando, com pequenas companhias avançando sobre as tradicionais".

Esta brusca queda, ocorrida em 2001, pode ser justificada pela grave crise enfrentada pelas companhias aéreas a nível mundial, que operam no transporte de passageiros, resultante da tragédia do 11 de setembro. Monçores (2005), que analisou os impactos do 11 de setembro no transporte aéreo internacional de passageiros, chegou à conclusão que houve uma influência bastante significativa sobre o saldo mensal da conta de despesas em viagens internacionais e o fluxo de passageiros embarcados em aviões comerciais para destinos fora do Brasil.

A tendência crescente pode resultar tanto do crescimento da economia, refletindo-se em maior número de passageiros transportados, 
como da desregulamentação parcial, assegurando maior flexibilidade de ajuste às empresas.

Gráfico 1. Evolução da Eficiência Média das Companhias

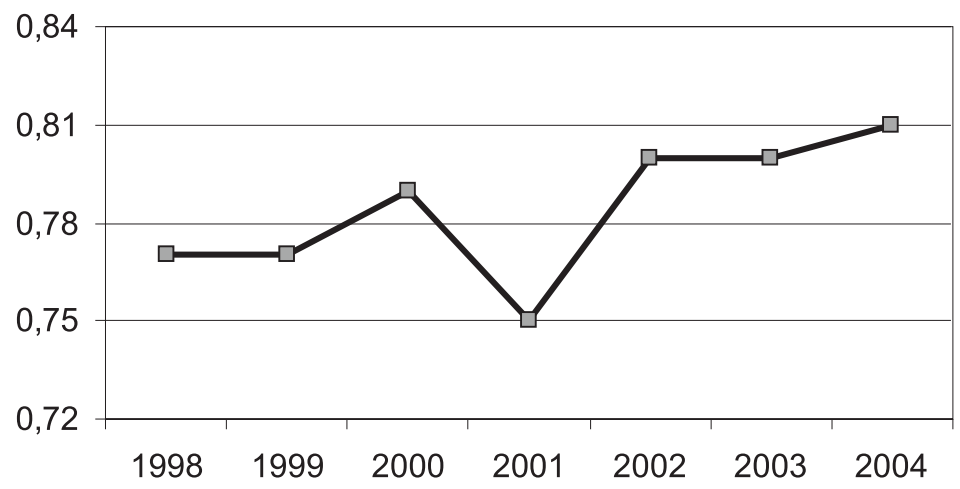

O gráfico 2 mostra a evolução da eficiência das seis maiores companhias aéreas operantes no Brasil ao longo do período analisado. São elas: GOL, Rio Sul, TAM, VARIG, VASP e Transbrasil.

Como se pode observar, a GOL, que deu início a suas operações com vôos domésticos em janeiro de 2001 , teve um crescimento de eficiência bastante elevado. Neste ano inicial, obteve uma parcela de $4,6 \%$ do total de passageiros transportados, pouco quando comparado as grandes empresas, e teve lucro de 58 milhões. Porém, de forma semelhante ao crescimento da eficiência, já em 2004 o percentual de mercado chegou a $20,3 \%$ e os lucros a 471 milhões de reais. É considerada das companhias que mais cresceram em períodos mais recentes no transporte aéreo de passageiros em todo o mundo. Opera com baixo custo, baixa tarifa e com uma frota de aeronaves 737 simplificada com classe única de serviços, uma das mais novas e modernas do setor, com baixos custos com manutenção, combustível e treinamento, e altos índices de utilização e eficiência.

A Rio Sul operou em todos os anos analisados e não obteve em nenhum deles $100 \%$ de eficiência. Ao contrário, sua eficiência vem caindo ao longo do tempo. Somente apresenta pequeno crescimento nos anos de 1998/1999 e de 2003/2004. Em 1998, foi a quinta maior companhia em termos de percentual de mercado com 9,94\% obtendo um lucro de pouco mais de 7 milhões. Em 1999, sua parcela de mercado teve aumento chegando a $13,5 \%$ e os lucros chegando a mais de 16 milhões. Porém, nos anos de 2001, 2002, 2003 e 2004 o 
percentual de mercado somente decresceu, chegando a 1,05\% no último ano e os lucros tornaram-se negativos. Esta análise de seu desempenho ao longo dos anos apresenta-se fortemente relacionada a sua eficiência.

A TAM é das companhias que tem as maiores médias de eficiência dos anos analisados. Vem se mantendo na fronteira de eficiência desde 1999 tendo, somente em 1998, coeficiente de rendimento abaixo de $100 \%$, sendo de $89 \%$. No ano de 1998 , a companhia detinha $11,8 \%$ do mercado e obteve prejuízo de 82,1 milhões. Porém, a partir do ano de 2000 , quando começou a operar com vôos internacionais, seus lucros só aumentaram juntamente com seu percentual de mercado que chegou, em 2004, a 33,2\%.

A VARIG vem ao longo dos anos aumentando sua eficiência. Somente em 2001 interrompe o crescimento e decresce de $89 \%$ para 83\%. A evolução de sua eficiência está altamente correlacionada aos seus lucros ao longo dos anos. Em 1998, obteve lucro de 1,1 bilhão que só cresceu chegando em 2000 a 1,78 bilhão. Em 2001, a queda da eficiência é acompanhada da queda dos lucros para 1,49 bilhão. Porém, em 2002 os lucros voltam a subir chegando ao seu valor máximo em 2003, que foi de 2,12 bilhões. O percentual de mercado se manteve quase inalterado ao longo dos anos. A crise da VARIG, que vem sendo analisada ao longo dos anos, não está relacionada a eficiência operacional mas a débitos elevados acumulados ao longo dos anos; na impossibilidade de honrar seus débitos, interrompe operação em período recente, sendo vendida ao longo de complexo processo de negociação.

Gráfico 2. Evolução da Eficiência das maiores Companhias Brasileiras

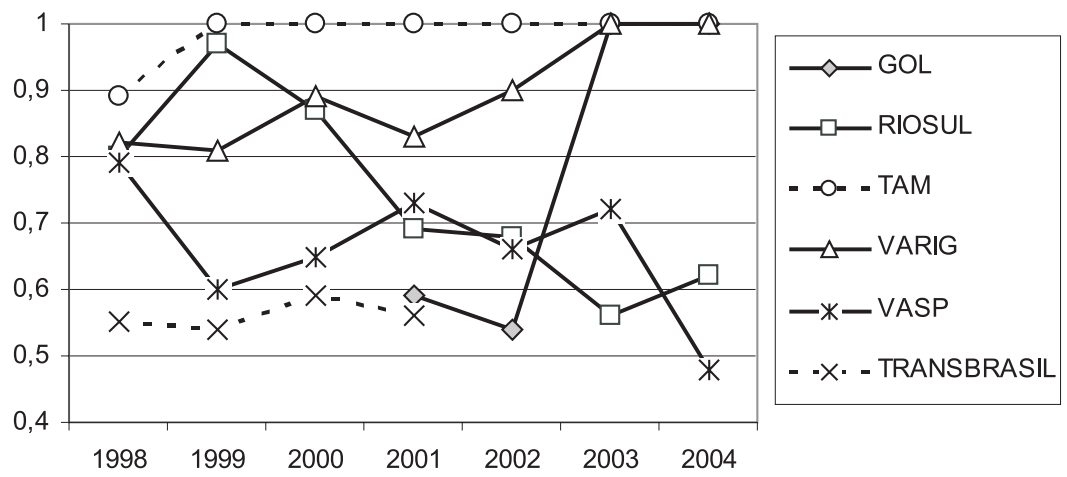


A VASP em 1998 apresentou coeficiente de eficiência acima da média das companhias, porém desde então, vem enfrentando uma elevada queda de sua eficiência chegando, em 2004, a um coeficiente de $48 \%$, um dos mais baixos entre todas as companhias nos anos analisados. Sua participação no mercado em 1998 foi de quase 16\%. Nos anos de 1999 e 2000 se manteve praticamente no mesmo patamar de $12 \%$ e de 2001 até 2004 vem caindo até 6,7\%. Segundo a Revista Época, "A participação da VASP no mercado da aviação civil vem caindo desde 2001, quando a GOL entrou no mercado". Com relação ao lucro, desde 1998, quando obteve lucro de 689 milhões, que o mesmo só decresce. Em 2004, a companhia teve um prejuízo de 268 milhões. Em janeiro de 2004 a companhia encerrou suas atividades.

Por fim, a Transbrasil operou sempre com eficiência abaixo da média e cessou suas operações em 2001. Até então, a companhia operava apenas aeronaves de última geração, possuindo 03 Boeing 767200, 02 Boeing 767-300ER (longo alcance) e 05 Boeing 737-300, num total de 10 aeronaves de baixo consumo. Sua parcela de mercado caiu bastante de 1998 a 2001. Em 1998, detinha 10,6\% do mercado, em 1999 , 9,8\%, em 2000, 7,7\% e finalmente em 2001, apenas 4,7\%. Dificuldades econômicas tais como falta de capital de giro, dívidas e falta de crédito abalaram de forma fulminante a empresa e acabaram por gerar seu encerramento provisório.

O número de vezes que cada companhia eficiente aparece como parâmetro para companhias ineficientes é mostrado na tabela 2. A importância da representatividade das companhias eficientes que servem de referência para as companhias ineficientes está no fato de que as práticas adotadas pelas eficientes podem servir para contribuir para um aumento da eficiência das ineficientes.

A companhia que foi referência o maior número de vezes foi a GOL no ano de 2003, companhia já citada como das que tem apresentado maior crescimento nos últimos anos. Seu crescimento de eficiência, em relação a 2002, foi pouco mais que $85 \%$ acompanhado também de um significativo aumento em seu percentual de mercado: em 2002 detinha $11 \%$ e em 2003 subiu para pouco mais de $18 \%$. Isto se reflete também em seus lucros. Em 2002, a companhia teve lucro de aproximadamente 160 milhões ao passo que em 2003 seu lucro foi de quase 493 milhões, que representa um impressionante aumento de $208 \%$. O ano de 2003 foi também marcado pelo início das operações com vôos internacionais pela companhia, que somente operava com vôos domésticos em 2002. 
Tabela 3. Número de vezes que cada sistema eficiente aparece como referencia para os sistemas ineficientes

\begin{tabular}{|c|c|c|c|}
\hline Sistema & $\begin{array}{c}\text { Número de vezes } \\
\text { como referência }\end{array}$ & Sistema & $\begin{array}{c}\text { Número de vezes } \\
\text { como referência }\end{array}$ \\
\hline GOL 2003 & 59 & TAF 2000 & 6 \\
\hline TAVAJ 1998 & 53 & TAM 1999 & 6 \\
\hline TAM 2000 & 48 & TAM 2003 & 4 \\
\hline ABAETE 2003 & 30 & VASP 1998 & 4 \\
\hline ABAETE 2002 & 28 & GOL 2004 & 3 \\
\hline PENTA 2004 & 17 & TAM 2004 & 2 \\
\hline PENTA 1998 & 15 & INTERBRASIL 2000 & 2 \\
\hline TRIP 2004 & 13 & ABAETE 1999 & 2 \\
\hline META 1999 & 11 & PANTANAL 2002 & 1 \\
\hline MERIDIONAIS 1998 & 11 & TAM 2002 & 1 \\
\hline TRIP 2003 & 10 & ABAETE 2004 & 0 \\
\hline PRESIDENTE 1999 & 9 & META 2004 & 0 \\
\hline ABAETE 1998 & 9 & VARIG 2004 & 0 \\
\hline PRESIDENTE 2000 & 7 & TAM 2001 & 0 \\
\hline VARIG 2003 & 6 & TOTAL 2001 & 0 \\
\hline META 2002 & 6 & PRESIDENTE 1998 & 0 \\
\hline
\end{tabular}

Fonte: Software EMS.

Outra companhia de grande porte que apareceu com elevado número de referências é a TAM em 2000, companhia também já citada que tem apresentado alto desempenho ao longo dos anos. No ano de 2000 foi quando começou a operar com vôos internacionais e obteve o segundo maior lucro entre as companhias, sendo de 377,4 milhões, ficando atrás somente da VARIG com 1,78 bilhão.

Há três pequenas companhias bastante eficientes. Uma delas encerra operação em 2000, a Presidente, e não merece análise. Uma outra, a Abaeté, é um caso interessante. É uma microempresa que opera em apenas três cidades do interior da Bahia. É estável e eficiente, mas atinge sua eficiência com operação muito restrita: representa $0,01 \%$ do total de passageiros do país. O caso mais interessante é o da TRIP, uma empresa regional do interior paulista que está em expansão. Eleva a eficiência nos dois últimos anos analisados: 2003 e 2004. Do interior de São Paulo expande-se para o Centro-Oeste, para o Sul, para a Amazônia e recentemente atinge o Nordeste. É exemplo de expansão ligada à eficiência. Recentemente estabeleceu coligação com a TAM em algumas linhas. Na época analisada representava $0,45 \%$ do mercado. 
Os resultados dos modelos econométricos 1 e 2 são apresentados nas tabelas 3 e 4 , respectivamente. No modelo 1, todas as três variáveis foram significantes. O consumo de combustível por $\mathrm{km}$ voados e o custo por passageiro foram significantes a $1 \%$ e a dummy para identificar se a companhia opera com vôos internacionais foi a $10 \%$. No modelo 2 , todas as duas variáveis foram significantes. $O$ número de empregados por passageiros foi a $5 \%$ e o percentual de mercado foi a $10 \%$.

Tabela 4. Resultados do Modelo 1

\begin{tabular}{|c|c|c|c|}
\hline Variável & Coeficiente & T-Stat & Significância \\
\hline Combustivel/Km & $-0,0126$ & $-3,45$ & 0,0007 \\
\hline Custo/Passageiro & $-0,0003$ & $-3,1$ & 0,0024 \\
\hline Voa Internacional & 0,0618 & 1,82 & 0,0707 \\
\hline Constante & 0,9083 & 28,47 & 0 \\
\hline \multicolumn{4}{|c|}{$\mathrm{r}^{2}=0,794$} \\
\hline
\end{tabular}

Fonte: Software WinRATS Pro 6.20.

O consumo de combustível por km voado das companhias é negativamente relacionado com sua eficiência. Este consumo é afetado por diversos fatores já mencionados como peso e tipo da aeronave, altitude de vôo, etc. O peso da aeronave depende do número de passageiros, da quantidade de combustível, bagagens, cargas (correio). Em reunião recente das companhias que integram a Associação de Transporte Aéreo Internacional (Iata), chegou-se à conclusão que um fator importante para redução do consumo de combustível é o adequado desenho das rotas. Isto afetando também a distribuição das cargas nos vôos. Outro fator importante citado é o tempo de preparação da decolagem nos aeroportos (UOL-ECONOMIA, 2006). Estes são fatores que dependem exclusivamente das companhias, ou seja, se as mesmas buscarem operar na fronteira de eficiência, seu consumo de combustível pode ser resumido significativamente diminuindo gastos.

O custo por passageiro é outro fator determinante que também está negativamente relacionado à eficiência das companhias. A redução dos custos eleva o desempenho operacional das empresas. A GOL opera com Boeing 737-700 de 144 lugares, enquanto que a Varig usa o mesmo 737-700 com 132 assentos. Isto significa que a cada onze decolagens da GOL, seria necessário à VARIG doze decolagens para transportar o mesmo número de passageiros. Essa diferença de assento nos Boeing 737-700 da GOL e da VARIG se deve ao fato de a 
GOL não ter as chamadas galleys, equipamentos robustos que servem para conservar e aquecer refeições, pois a companhia não as disponibiliza durante vôo. Isso tem impacto, além do valor da refeição por passageiro, no espaço para mais lugares, já mencionado, no peso da aeronave e também no tempo de preparação para decolagem na reposição das refeições nas conexões.

Com relação a variável dummy utilizada para distinguir companhias que operam somente com vôos domésticos e companhias que operam com vôos domésticos e internacionais, o resultado é que as companhias que operam com vôos domésticos e vôos internacionais são mais eficientes. O coeficiente médio de eficiência das companhias que operam com vôos nacionais e internacionais é de 0,843 enquanto que o coeficiente médio das companhias que operam somente com vôos domésticos é de 0,754, ou seja, as companhias que operam também com vôos internacionais tem coeficiente de eficiência, em média, 11,87\% maior que as demais.

Tabela 5. Resultados do Modelo 2

\begin{tabular}{|c|c|c|c|}
\hline Variável & Coeficiente & T-Stat & Significância \\
\hline Pessoal/Passageiro & $-22,2738$ & $-2,06$ & 0,0412 \\
\hline \%Mercado & 0,0035 & 1,87 & 0,063 \\
\hline Constante & 0,8217 & 33,82 & 0 \\
\hline \multicolumn{4}{|c|}{$\mathrm{r}^{2}=0,784$} \\
\hline
\end{tabular}

Fonte: Software WinRATS Pro 6.20.

Com relação à variável número de funcionários por passageiro, são mais eficientes as companhias que operam com menor quadro de pessoal por passageiro. Um menor quadro de pessoal, dado o número de passageiros transportados, acaba por gerar um menor custo para a companhia, o que corrobora com a correlação obtida na análise das variáveis. Conclui-se para essa variável que um método inovador, como a venda de passagens on-line, reduz a relação pessoal por passageiro, aumentando assim o índice de eficiência como mostrado no modelo 2.

Com relação ao percentual de mercado que a companhia detém, quanto maior esse valor mais eficiente é a companhia. Ou seja, empresas que crescem no percentual de mercado, impactam positivamente na eficiência. Como exemplo, a GOL que começou em 2001 com 4,6\%, tendo coeficiente de eficiência de 0,59, e em 2004 atingiu 20,3\% com um coeficiente de eficiência de 1,00. 


\section{Considerações Finais}

A analise da situação atual e da evolução do desempenho das companhias aéreas brasileiras é de extrema importância, pois pode destacar aspectos que venham a contribuir para um melhor e mais adequado desenvolvimento do setor. Para analisar estes aspectos primeiramente foram calculados os coeficientes de eficiência das companhias através do modelo de análise de envoltória de dados (DEA) com orientação para produto e com retornos variáveis de escala. Em seguida, estes coeficientes foram analisados em dois modelos econométricos para identificar a influência de alguns fatores.

Os resultados obtidos no modelo DEA mostraram que as companhias brasileiras, em média, apresentam uma leve tendência de crescimento da eficiência ao longo do período analisado. Esta tendência é interrompida somente no ano de 2001, quando as companhias tiveram uma redução na eficiência causada possivelmente pela tragédia do 11 de setembro. Os resultados mostraram também que dentre as seis maiores companhias brasileiras, somente três estavam operando, em 2004, na fronteira de eficiência: GOL, TAM e VARIG. As demais: Rio Sul e VASP apresentaram queda significativa de eficiência ao longo do tempo e a Transbrasil esteve operando sempre com baixa eficiência até interromper suas operações em 2001. Entre as pequenas eficientes, a TRIP mostra como a eficiência está ligada à expansão da empresa. A GOL destacou-se como a companhia que o maior número de vezes foi referência de desempenho para as demais. É seguida, entre as grandes pela TAM. As pequenas Abaeté e TRIP também servem como referência.

Com relação aos modelos econométricos utilizados para analisar a influência de algumas variáveis sobre a eficiência, o modelo 1 mostrou que o consumo de combustível por km e o custo por passageiro das companhias estão negativamente relacionados ao coeficiente de desempenho. Já a dummy para identificar se a companhia opera também com vôos internacionais apresentou-se positivamente relacionada. No modelo 2, o número de funcionários por passageiro apresentou-se negativamente relacionado, ou seja, evidencia o fato de companhias como a GOL que vende alto percentual de passagens via Internet reduzindo altamente seus custos. O modelo 2 também identificou que empresas que detém maior percentual de mercado são mais eficientes.

Em conclusão, as empresas mais eficientes tendem a aumentar sua participação no mercado e algumas ineficientes podem se tornar inviáveis, vindo a encerrar suas atividades. A busca de eficiência 
centra-se na redução de combustível por km e no custo dos passageiros, implicando na escolha correta de aeronaves e rotas e na melhoria da escala de operação e na redução do número de funcionários por passageiro, mas sem prejudicar a qualidade e a segurança do vôo.

\section{Referências Bibliográficas}

AIGNER $\mathcal{E}_{3} \mathrm{CHU}$, X. On Estimating the Industry Production Function. American Economic Review, v. 5, n. 4, p. 826-839, 1968.

CRUISE FLIGHT - Aircraft Operating Manual 737-600. Fuel Load Estimation 737-600. Seção 2, p. 7, 2003.

BANKER, R. D.; CHARNES, A.; COOPER, W.W. Some models for estimating technicaland scale inefficiencies. Management Science, n. 30, p. 1078 -1092, 1984.

BENJAMIN, J.; OBENG, K. The effect of policy and background variables on total factor productivity for public transit. Transportation Research 24B (1), p. 1-14, 1990.

BURMANN, P. Análise Prospectiva do Mercado de Carga Aérea no Brasil. 2000. Tese (Mestrado), COPPE/UFRJ, Rio de Janeiro, 2000.

CAVES, D. W.; LAURITS C.; MICHAEL W. T. Economies of Density versus Economies of Scale: Why Trunk and Local Service Airline Costs Differ? Rand Journal of Economics 15(4), 1984.

CHARNES, A, COOPER, W.W., RHODES, E. Measuring the efficiency of decision making units. European Journal of Operational Research, 2, p. 429-444, 1978.

DAC. Anuário de Dados Estatísticos - 1998 a 2004. Departamento de Aviação Civil, Rio de Janeiro, 1999 a 2005.

FARRELL, M. J. The measurement of productive efficiency. Journal of the Royal Statistical, 1957.

GREENE, William. Econometric Analysis. New Jersey: Prentice Hall, p. 222, 2003.

GUJARATI, Damodar. N. Econometria básica. São Paulo: Makron Books, 2000.

IPEA. Boletim de Conjuntura do IPEA n. 59, novembro de 2002.

JORNAL DA GLOBO. Briga no Ar. Publicado dia 7 de fevereiro. Disponível em: < http:/ /jg.globo.com/JGlobo/0,19125,VTJ0-2742-20060207-150077,00.html> . Acesso em: junho de 2006.

MARTÍN, J. C.; NOMBELA, G.; ROMERO, M. European Airline Industry: A cost Analysis and Economic Performance Evaluation. Artigo ainda não publicado, 1999.

PASIN, J.A. B.; LACERDA, S. M. A Reestruturação do Setor Aéreo e as Alternativas de Política para a Aviação Comercial no Brasil. Revista do BNDES, v. 10, n. 19. Junho de 2003.

MONÇORES, P. J. Análise da Influência do 11 de setembro e da taxa de câmbio sobre o transporte aéreo internacional de passageiros no Brasil. 2005. Disponível em: <http:// scholar.google.com/url?sa =UËq =http://www.sfrancisco.edu.br/pdf/art_cie/ art_06.pdf > . Acesso em: junho de 2006.

PINTO, V. C. A Crise na Aviação Brasileira. 2003. Disponível em: <www.senado.gov.br/ conleg/artigos/direito/ACrisenaAviacaoBrasileira.pdf> . Acesso em: junho de 2006.

RÉGIS, F. A. P. Eficiência de Custo no Setor Bancário Brasileiro. Recife. 2001. 115 fls. Dissertação (Mestrado) - Universidade Federal de Pernambuco, 2001. 
REVISTA ÉPOCA. Histórico da Crise na VASP. Disponível em: < http://revistaepoca. globo.com/Epoca/0,6993,EPT900553-1655,00.html>. Acesso em: junho de 2006.

SAMPAIO, B. R.; SAMPAIO, Y.; SAMPAIO, L. M. B. Eficiência de Sistemas de Transporte Público no Nordeste com Análise Envoltória de Dados. Revista Econômica do Nordeste, abr/jun 2006, no prelo.

SOARES DE MELLO, J. C. C. B.; ÂNGULO MEZA, L.; GOMES, E. G.; SERAPIÃO, B. P. Estellita Lins, M. P. Análise de Envoltória de Dados no Estudo da Eficiência e dos Benchmarks para Companhias Áreas Brasileiras. Pesquisa Operacional, v. 23, n. 2, p. 325-345, maio a agosto de 2003.

UOL-ECONOMIA. Companhias aéreas tentam reduzir gastos com a alta do petróleo. Disponível em: <http://noticias.uol.com.br/economia/ultnot/efe/2006/06/06/ ult1767u68801.j.htm>. Acesso em: junho 2006. 